\title{
EXPERIMENTAL ASSESSMENT OF FERRITIC STAINLESS STEEL COMPOSITE SLABS
}

\author{
Dr Katherine Cashell \\ Brunel University London \\ London UB8 3PH, UK \\ katherine.cashell@brunel.ac.uk \\ Nancy Baddoo \\ Steel Construction Institute \\ Ascot, Berkshire SL5 7QN, UK \\ n.baddoo@steel-sci.com
}

\begin{abstract}
This paper describes investigations into the structural behaviour of ferritic stainless steel floor decking in composite construction. Although commonly used in the automotive and industrial sectors, structural applications of ferritic stainless steels are rare owing to a relative lack of knowledge, performance data and design guidance. These materials display considerably better atmospheric corrosion resistance than carbon steels, as well as having good ductility, formability and excellent impact resistance. As part of a wider investigation into the use of ferritic stainless steels in structural applications, an experimental study has been undertaken to assess the viability of using these materials for the profiled decking in composite floors. The shear connection behaviour between the steel beams and the composite slab is clearly critical and this is influenced by the through-deck welding process of the shear connectors. The practicality of this welding technique is assessed and described in this paper. Furthermore, the results of a series of push tests are presented. These enable the resistance of the shear connectors to be established and compared with the strengths specified in EN 1994-1-1 for composite slabs using galvanized steel decking.
\end{abstract}

\section{INTRODUCTION}

Ferritic stainless steels are low cost, price-stable, corrosion-resistant materials which are widely used in the automotive and domestic appliance sectors. They are a family of 'utility' stainless steels which display considerably better atmospheric corrosion resistance than carbon steels, as well as having good ductility, formability and excellent impact resistance. Nevertheless, structural applications are scarce owing to a lack of suitable information and design guidance. It is in this context that a major collaborative project is underway in Europe entitled Structural Applications of Ferritic Stainless Steels (or SAFSS). The principal aim of this study is to develop the information needed for comprehensive structural design guidance to be included in relevant parts of the Eurocodes and other accompanying standards/guidance. Although the research has general applicability to the use of ferritic stainless steel, there is a particular focus on trusses and space frame structures as well as exposed decking in composite floor systems, the latter of which is relevant to the current paper. 
Steel-concrete composite construction is a popular choice amongst engineers and designers as it represents a very efficient use of materials, providing quick, cost effective and sustainable construction (Simms and Hughes, 2011). Typical ingredients include steel decking, slab reinforcement, shear connectors, structural steel section and the concrete slab, as shown in Figure 1. The use of steel-concrete composite floor slabs is well established and the design approach is presented in Eurocode 4 (EN 1994-1-1, 2004). It is estimated that the European market size for decking in composite floor systems is $60-80,000$ tonnes per annum. However, the use of stainless steel for the decking has not been explored in any great detail, although it offers two distinct advantages over galvanized steel, which may be favourable in certain circumstances:

i. Corrosion resistance - this may be important in applications with exposed decking or in other sensitive environmental conditions, e.g. during the construction stage, or in a car park.

ii. Thermal capacity - it has been shown that the thermal mass in floor slabs can be used to regulate temperatures in the structure thereby reducing the need for additional cooling and heating measures (Barnard and Ogden, 2006; Kendrick and Wang, 2007). This is optimized by using profiled slabs as the exposed area is greater than in flat slabs and also by having an exposed metal deck to allow good convective and radiative heating/cooling. Whilst the thermal performance of galvanised and stainless steel has not been shown to differ significantly, stainless steel is more likely to be exposed as it provides a more attractive appearance.

Ferritic stainless steels can offer a cost-effective solution in composite floors. However, before this technology can be further developed, it is necessary to satisfy the required structural performance of composite slabs using profiled decking rolled from ferritic stainless strip steel. Apart from the SAFSS project, no other research programme looking at the use of stainless steel in composite floor systems is known to the authors.

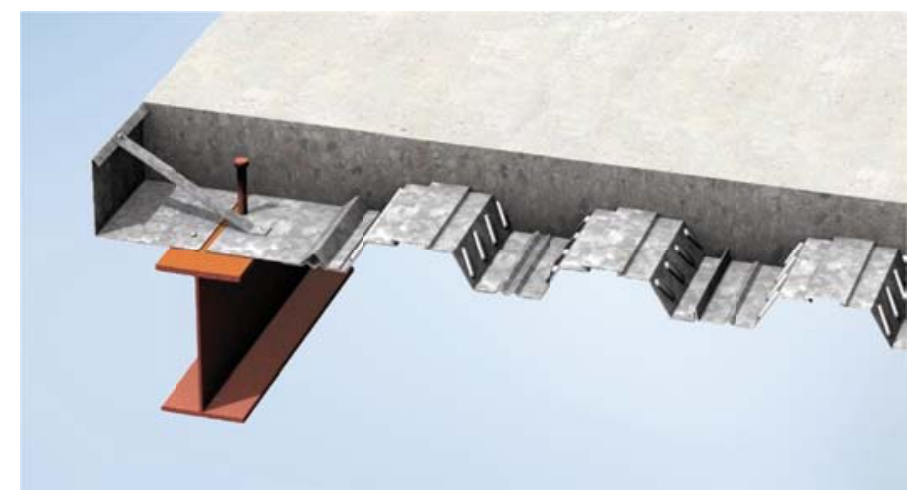

Figure 1 - Steel-concrete composite construction (image available from the $\mathrm{SCl}$ )

Historically, the performance of shear connectors has been established using small-scale push test specimens, where a small number of shear studs are embedded in a concrete section and welded to a steel section which is then loaded whilst the concrete section is held in position. This type of test is described in Eurocode 4 (2004) and the essence of the test has remained unchanged since the 1930's (Hicks, 2007). However, it is important to note that the validity of these tests has come into question in recent years as comparisons have shown that that the specimens have lower resistances and ductility than composite beams with the same material properties, cross-section and decking geometry (e.g. RamboRoddenberry, 2002; Bradford et al., 2006; Hicks, 2007). The reason for this lies in the loading and restraint conditions of the push tests, which are different to those experienced in 
a composite beam. In particular, the vertical forces and negative bending in the slab at the line of the shear connectors are currently ignored.

Nevertheless, a cost-effective and straight-forward alternative to the standard push test has yet to be developed and introduced in design guidance (although it is currently being investigated in a major European project entitled "Development of improved shear connection rules in composite beams" which is being coordinated by the Steel Construction Institute and funded by the Research Fund for Coal and Steel), and therefore the tests adopted in this programme are as specified in Eurocode 4. It is acknowledged that the push tests may not give the full impression of the composite performance but they can still give a useful insight into the most salient parameters and provide a basis for comparison with other materials. A primary objective of this study is to gain an insight into the effect of different shear connection arrangements on the composite performance.

This paper provides a background to the SAFSS project, followed by a brief description of ferritic stainless steel. Thereafter, a discussion on composite behaviour will be given as well as a description of the experimental investigation into the composite performance of ferritic stainless steel-concrete composite slabs. A series of 8 push composite tests has been completed at Brunel University in order to assess the shear connection behaviour and these will be discussed together with the findings from the through-deck welding trials. More detailed discussion is available elsewhere (Cashell and Baddoo, 2014).

\section{SAFSS PROJECT}

The SAFSS project is a 3-year collaborative project which commenced in mid-2010 with a view to increasing the structural use of ferritic stainless steels. The project is largely funded by the European Union Research Fund for Coal and Steel (RFCS) with additional support from Aperam, Acerlnox and Outokumpu Stainless Oy and is being coordinated by the Steel Construction Institute. The project has been divided into eight separate work packages with various partners working on each. The work packages (WP's) include studies into: (WP1) Mechanical properties; (WP2) Structural performance of light gauge members; (WP3) Structural performance of steel decking in composite floor systems; (WP4) Structural performance at high temperatures; (WP5) Structural performance of welded connections; (WP6) Structural performance of bolted and screwed connections; (WP7) Corrosion resistance; and (WP8) Design guidance and implementation into the Eurocodes. The study discussed in this paper is relevant to WP3.

\section{FERRITIC STAINLESS STEELS}

Ferritic stainless steels do not contain significant quantities of nickel and are therefore cheaper and relatively price-stable compared with austenitic stainless steels. Ferritics also differ from the more commonly-used austenitic stainless steels in that they have higher mechanical strengths (approximately $250-330 \mathrm{~N} / \mathrm{mm}^{2} 0.2 \%$ proof strength), are magnetic, have lower thermal expansion, higher thermal conductivity and are easier to cut and work.

The mechanical and physical properties of ferritics make them suitable for use in composite floor slabs where an attractive metallic surface finish is desirable. Unlike galvanised steel, ferritic stainless steels have a naturally occurring corrosion resistant surface layer so there is no requirement for applying protective surface layers and no remedial work or corrosion risk at cut edges in most normal applications. Furthermore, ferritics are easy to recycle compared to galvanised steel where the zinc from the galvanised coating must be removed prior to re-melting the steel.

Three of the 'traditional' ferritic grades are covered in the American SEI/AISI Specification for design of cold-formed stainless steel structural members (SEI/AISI, 2002) for thicknesses up to $3.8 \mathrm{~mm}$. The South African (South African Bureau of Standards, 1997) and 
Australian/New Zealand (Standards Australia Standards New Zealand, 2001) structural stainless steel standards take similar approaches. The Eurocode for structural stainless steel, EN 1993-1-4 (2006) states it is applicable to three traditional ferritic grades (grades $1.4003,1.4016$ and 1.4512), however, the guidance is almost exclusively derived from work on austenitic and duplex stainless steels and in many cases ferritic-specific guidance is missing. EN 1993-1-4 refers to a number of clauses in other parts of Eurocode 3 such as EN 1993-1-2 (2005), 1-8 (2005), 1-9 (2005) and 1-10 (2005) which have not been validated for ferritic stainless steels. One exception is that EN 1993-1-2 (2005) includes data on one ferritic grade.

\section{COMPOSITE BEHAVIOUR}

In composite structures, the applied loads are transferred between the floor slab and the beams through shear connectors which are embedded in the concrete slab and welded to the steel beam. The capacity of these studs is typically established experimentally through push tests, although there are shortcomings to this approach, as presented earlier in this paper. International design standards such as Eurocode 4 (EN 1994-1-1, 2004) provide theoretical models for predicting the shear resistance of the shear studs.

The Eurocode 4 theoretical model is presented in Sections 6.6.3.1 and 6.6.4.2 of the code. When stud connectors are welded within ribs of profiled steel decking, their resistance is reduced compared with their resistance in a solid slab. To account for this, Eurocode 4 applies an empirically-derived reduction factor $\left(k_{t}\right)$ which is multiplied to the design resistance for a shear stud in a solid slab $\left(P_{R d}\right)$ to give the final shear stud resistance (referred to as $\mathrm{P}_{\mathrm{Rd} \text {,rib }}$ hereafter). However, it is noteworthy that Eurocode 4 provides no guidance as to how the standard solid slab specimen should be adjusted when decking is present, which has given rise to a large degree of scatter in test results (Hicks, 2007).

The reduction factor $k_{t}$ is defined as:

$k_{\mathrm{t}}=\frac{0.7}{\sqrt{\mathrm{n}_{\mathrm{r}}}} \frac{\mathrm{b}_{0}}{\mathrm{~h}_{\mathrm{p}}}\left(\frac{\mathrm{h}_{\mathrm{sc}}}{\mathrm{h}_{\mathrm{p}}}-1\right)$ but $k_{\mathrm{t}} \leq 0.85$ for studs welded through profiled steel sheeting and $k_{\mathrm{t}} \leq$

0.75 for profiled sheeting with holes.

where:

$\mathrm{b}_{0} \quad=$ the width of a trapezoidal rib at mid-height of the profile;

$\mathrm{n}_{\mathrm{r}} \quad=$ is the number of stud connectors in one rib at a beam intersection,

$h_{p} \quad=$ the height of the steel sheeting measured to the shoulder of the profile;

$\mathrm{h}_{\mathrm{sc}}=$ the as-welded height of the stud, but not greater than $h_{\mathrm{p}}+75 \mathrm{~mm}$.

$P_{R d}$ is defined as being the lesser of two values calculated using Equation (6.18) and (6.19) in Eurocode 4 for steel and concrete failure, respectively. Equation (6.18) determines the resistance based on the strength of the steel, presented here as Equation (2):

$\mathrm{P}_{\mathrm{Rd}}=\frac{0.8 \mathrm{f}_{\mathrm{u}} \pi \mathrm{d}^{2} / 4}{\gamma_{\mathrm{V}}}$

where:

$f_{u} \quad$ the specified ultimate tensile strength of the material of the stud but not greater than $450 \mathrm{~N} / \mathrm{mm}^{2}$ for a profiled slab;

d the diameter of the shear connectors; 
$\gamma_{\mathrm{V}} \quad$ the partial factor.

Equation (6.19) in Eurocode 4 determines the resistance based on the strength of the concrete, presented here as Equation (3):

$\mathrm{P}_{\mathrm{Rd}}=\frac{0.29 \alpha \mathrm{d}^{2} \sqrt{\mathrm{f}_{\mathrm{ck}} \mathrm{E}_{\mathrm{cm}}}}{\gamma_{\mathrm{V}}}$

where:

a a function of the dimensions of the deck and shear connectors;

$f_{c k} \quad$ the characteristic cylinder strength of the concrete;

$E_{c m}$ the secant modulus of elasticity of the concrete.

Annex $B$ in Eurocode 4 states that the characteristic slip capacity $\delta_{u k}$ should be taken as the maximum slip capacity of a specimen $\delta_{u}$ reduced by $10 \%$, where $\delta_{u}$ is the slip corresponding to the characteristic load level $\left(P_{\mathrm{Rk}}\right)$. In Clause 6.6.1.1(5) of that standard, a shear connector is defined as ductile if the characteristic slip capacity is at least $6 \mathrm{~mm}$, and the minimum degree of shear connection rules in the standard are calibrated for this ductility.

\section{EXPERIMENTAL PROGRAMME}

The primary objective of the laboratory experiments is to gain a greater understanding of the composite performance of slab specimens using ferritic stainless steel decking by completing a series of standard push tests. A number of parameters can affect the load-slip characteristics between the steel and the concrete, such as the way that the stud is welded to the steel section, continuity of the decking and the strength of the concrete. The focus in these tests is to ensure that the composite performance of specimens using ferritic decking is, at least, as good as that when galvanised decking is used and also to investigate the effect of different construction arrangements.

Prior to undertaking the main experimental programme, which consists of 8 push tests, it was important to conduct welding trials in order to verify the practicality of the through-deck welding technique commonly used in the UK. The welding trials were completed at Hare Decking Ltd (formerly Richard Lees Steel Decking) in the UK, where $19 \mathrm{~mm}$ carbon steel shear studs were welded through ferritic stainless steel sheeting to the structural steel beams using the same technique as used for regular galvanised steel decking (Figure 2). Once welded into position, they were subjected to the standard tests performed on welded shear studs in construction, i.e. the ring and bend tests (Figure 3); all welds passed these tests. Importance was given to subjecting the ferritic specimens to the same standard of testing as is commonly used on-site for galvanised decking.

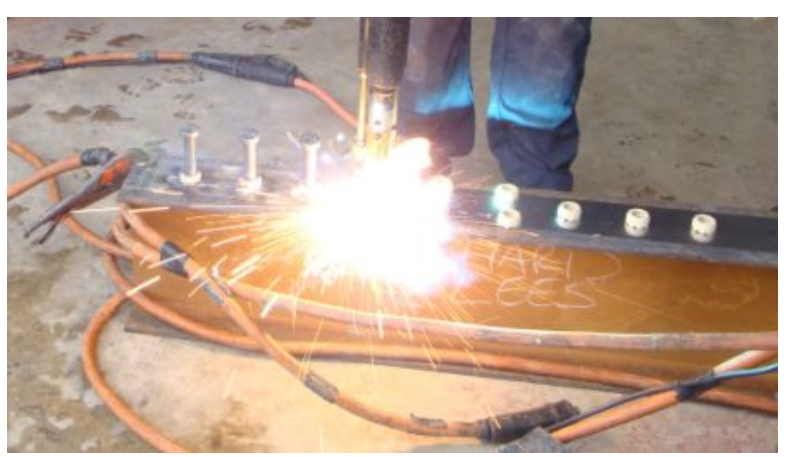

Figure 2 - Through deck welding

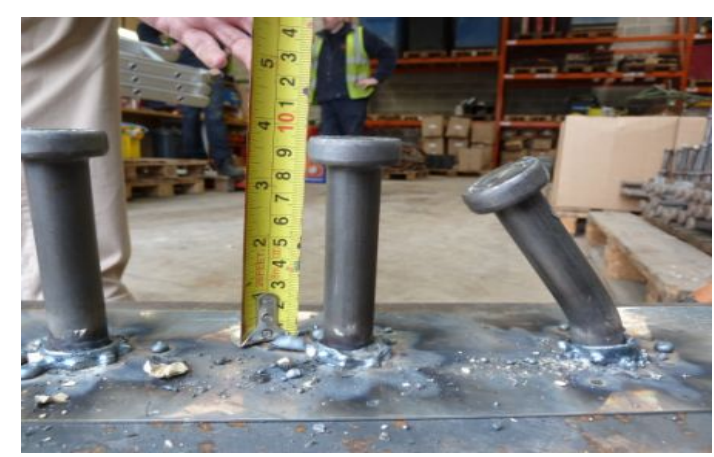

Figure 3 - Bend test and 'left after weld 


\section{height'}

Further observations from the trials were that the welds were very satisfactory and all welds were found to have good collars and to be of correct 'left after weld height', i.e. $95 \mathrm{~mm}$ 'left after weld height' for a shear stud which was originally $100 \mathrm{~mm}$ in height, as shown in Figure 3 . Based on the results of these trials, it can be deduced that there is no greater risk using ferritic decking than using galvanised decking from the welding persipective. Once the welding trials were completed with satisfactory results, the push test specimens were prepared at the same location.

\section{Push tests}

A total of 8 push tests were completed at Brunel University, all of which used Arcelor Mittal Cofraplus 60 decks (as shown in Figure 4) with a thickness of $0.8 \mathrm{~mm}$ in grade 1.4003 ferritic stainless steel. The tests were completed in accordance with EN1994-1-1 Annex B, differing slightly in that the code describes a flat concrete slab without steel decking whereas the test specimens were profiled with ferritic stainless steel sheeting. Structural tees were used rather than universal column sections to enable both sides of the specimen to be cast at the same time, thus ensuring consistent concrete properties within each specimen. The general construction of the test specimens is shown in Figure 5. Anti-cracking mesh (A193) was included in each specimen as shown in the diagram. There were 2 shear studs in each individual slab for all tests, thus resulting in 4 shear studs per test.
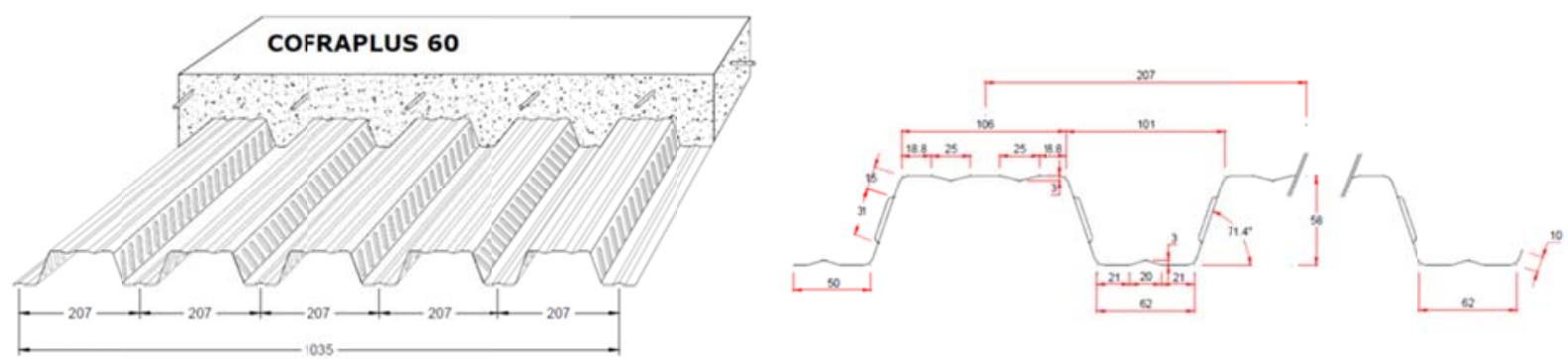

Figure 4 - Cofraplus 60 decking

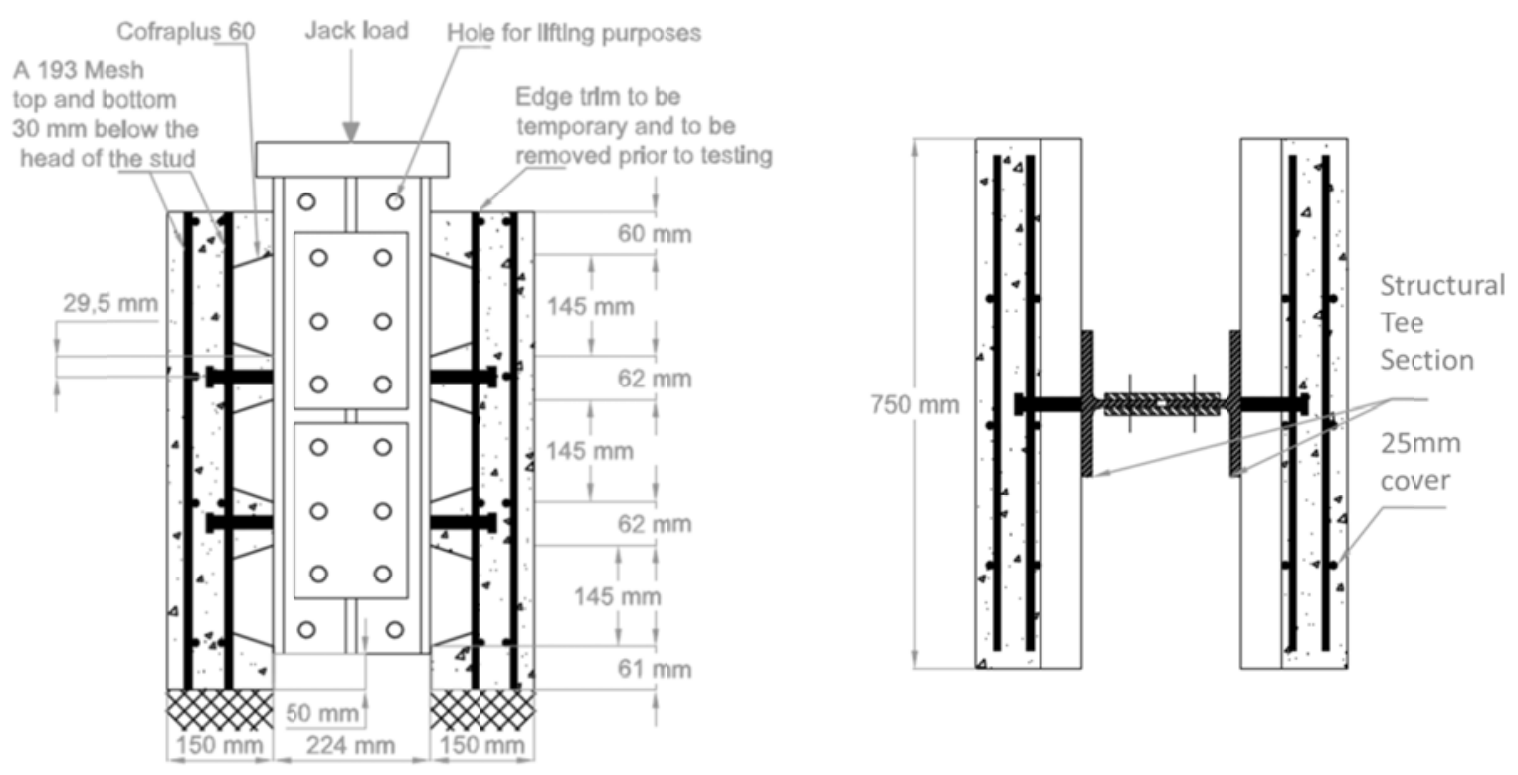

Figure 5 - Test specimen 
Whilst through-deck welding is popular in the UK, other parts of Europe typically use studs welded directly to the steel beam and decking with pre-punched holes. Both of these scenarios were examined in the current programme with three identical specimens of each category tested. The decking was rolled with a central stiffener in the centre of the trough which had to be hammered flat local to the stud position in the through-deck welded specimens to ensure direct electrical contact through the components as well as the integrity of a homogeneous weld. There was insufficient space to offset the shear stud. In order to ensure that this process did not affect the integrity of the weld, the two remaining tests in the programme had shear studs welded to the steel beam through a narrow strip (100 mm wide) of flat ferritic stainless steel sheeting with the same material properties as the profiled sheeting. A profiled sheet with pre-punched holes was then placed over the studs. The test programme is summarised in Table 1.

Table 1 - Push-out test programme

\begin{tabular}{|c|c|c|c|c|c|}
\hline Series: & $\begin{array}{l}\text { Number } \\
\text { of tests: }\end{array}$ & Details & $\begin{array}{l}\text { Shape of } \\
\text { slab }\end{array}$ & $\begin{array}{l}\text { Continuity of } \\
\text { deck beyond } \\
\text { weld? }\end{array}$ & $\begin{array}{l}\text { Through- } \\
\text { deck } \\
\text { welded? }\end{array}$ \\
\hline 1 & 2 & $\begin{array}{l}\text { Studs welded through } \\
\text { narrow flat sheet }\end{array}$ & Profiled & No & Yes \\
\hline 2 & 3 & $\begin{array}{l}\text { Studs welded through } \\
\text { continuous profiled deck }\end{array}$ & Profiled & Yes & Yes \\
\hline 3 & 3 & No through-deck welding & Profiled & No & No \\
\hline
\end{tabular}

In each case the test specimens were loaded to failure by applying a hydraulic jack to a plate on top of the steel tees. Load was transferred to the concrete through the shear studs. In accordance with EN 1994-1-1, the load was first applied in increments up to $40 \%$ of the expected failure load and then cycled 25 times between $5 \%$ and $40 \%$ of the expected failure load. In each test, following the cycles, the load and displacement were gradually increased until failure occurred, typically by concrete pull-out, which was accompanied by a significant reduction in load capacity. The longitudinal slip between each composite slab and the steel section was measured continuously using displacement transducers, as was the lateral displacement of the slabs.

\section{Results}

Load-slip relationships for Series 1, 2 and 3 are presented in Figures 6-8 respectively whilst the Figure 9 is an image of a specimen after testing. A summary of all the experimental data is presented in Table 2, where $f_{c k}$ refers to the compressive cylinder strength of the concrete on the day of testing (taken as the average of three cylinders), $P_{f}$ is the failure load observed in the tests and $P_{R k}$ is the characteristic resistance per stud equal to $90 \%$ of $P_{f}$ divided by the number studs (4 in this case), as defined in Eurocode 4 Annex B (EN 1994-1-1, 2004). $\delta_{u}$ is the slip corresponding to $P_{R k}$ whereas $\delta_{u k}$ is the characteristic slip equal to $\delta_{u}$ reduced by $10 \%$. $P_{R d, r i b}$ is the design resistance as described previously. The yield $\left(f_{y}\right)$ and ultimate $\left(f_{u}\right)$ strengths of the ferritic decking were $326 \mathrm{~N} / \mathrm{mm}^{2}$ and $480 \mathrm{~N} / \mathrm{mm}^{2}$, respectively, based on taking the average of 4 tensile test coupons. On the other hand, the yield and ultimate strengths of the shear studs were $446 \mathrm{~N} / \mathrm{mm}^{2}$ and $488 \mathrm{~N} / \mathrm{mm}^{2}$, respectively. 


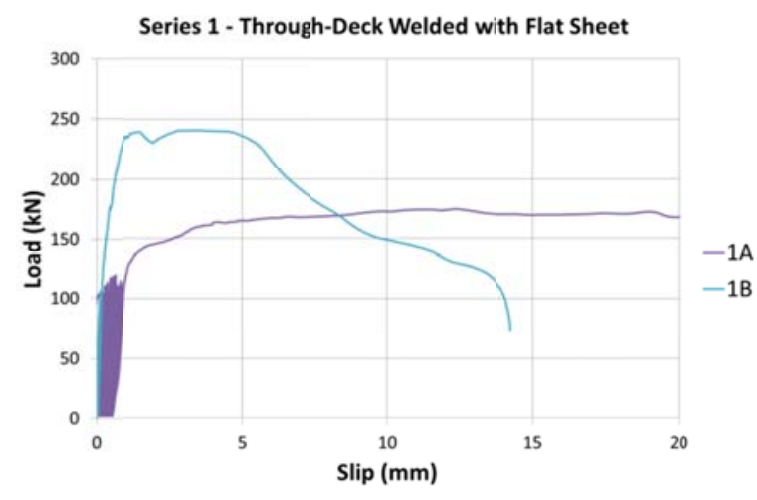

Figure 6 - Load-slip curves for Series 1

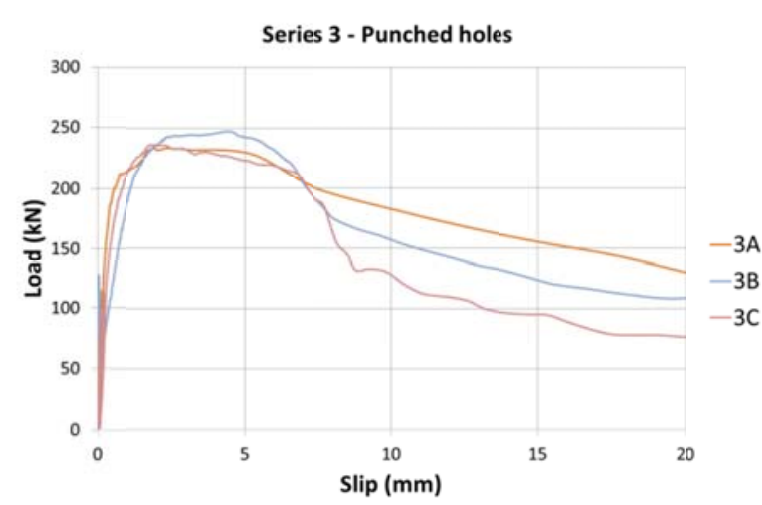

Figure 8 - Load-slip curves for Series 3

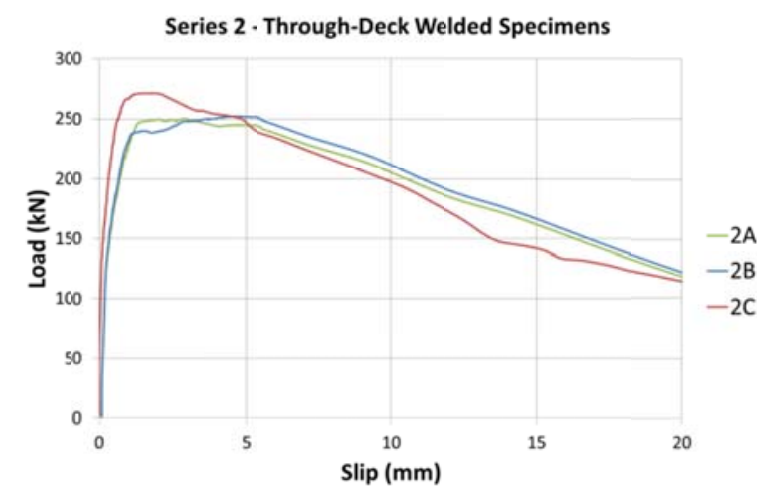

Figure 7 - Load-slip curves for Series 2

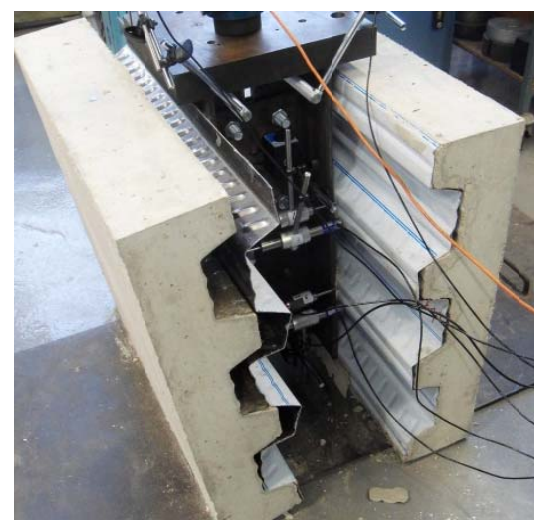

Figure 9 - Failed specimen after testing

Table 2 - Results of push tests

\begin{tabular}{c|ccccccc}
\hline Specimen & $\begin{array}{c}\mathrm{f}_{\mathrm{ck}} \\
\left(\mathrm{N} / \mathrm{mm}^{2}\right)\end{array}$ & $\begin{array}{c}\mathrm{P}_{\mathrm{f}, \mathrm{total}} \\
(\mathrm{kN})\end{array}$ & $\begin{array}{c}\mathrm{P}_{\mathrm{Rk}} \\
(\mathrm{kN})\end{array}$ & $\begin{array}{c}\delta_{\mathrm{u}} \\
(\mathrm{mm})\end{array}$ & $\begin{array}{c}\delta_{\mathrm{uk}} \\
(\mathrm{mm})\end{array}$ & $\begin{array}{c}\mathrm{P}_{\mathrm{Rd}, \text { rib }} \\
(\mathrm{kN})\end{array}$ & $\mathrm{P}_{\mathrm{Rk}} / \mathrm{P}_{\mathrm{Rd}, \mathrm{rib}}$ \\
\hline 1-A & 35.82 & 174.66 & 43.66 & 22.07 & 19.86 & 64.07 & 0.69 \\
1-B & 44.44 & 234.70 & 58.68 & 6.43 & 5.78 & 64.07 & 0.92 \\
2-A & 30.05 & 249.72 & 62.43 & 7.67 & 6.90 & 64.07 & 0.98 \\
2-B & 41.26 & 245.19 & 61.30 & 9.62 & 8.66 & 64.07 & 0.96 \\
2-C & 34.29 & 270.93 & 67.73 & 5.61 & 5.05 & 64.07 & 1.06 \\
3-A & 37.54 & 231.66 & 57.92 & 6.77 & 6.09 & 64.07 & 0.91 \\
3-B & 29.59 & 244.20 & 61.05 & 6.58 & 5.92 & 64.07 & 0.96 \\
3-C & 39.25 & 232.40 & 58.10 & 6.87 & 6.18 & 64.07 & 0.91 \\
\hline
\end{tabular}

\section{Observations and analysis}

During the 25 cycles between $5 \%$ and $40 \%$ of the expected failure load, the specimens remained in good condition with no visible cracks, although concrete movement could be heard. At about $80-90 \%$ of the peak load and a slip of around $1 \mathrm{~mm}$, visible delamination occurred between the concrete slab and the decking. With the addition of more load, the concrete began to visibly and audibly crack. Failure was typically accompanied by a notable drop in the load-carrying capacity of the specimen. 
All of the specimens demonstrated concrete pull-out failure around the shear connectors although one stud was found to have sheared off in Specimen 3-C. It is impossible to know exactly when this happened although it is likely that it was after the concrete had failed as the displacement increased. After each test, the concrete slab was removed from the profiled sheeting, which was very easy as no bond remained. Figure 10 shows Specimen 3A without the steel deck where the evidence of concrete pull-out can be seen, whereas the steel deck from this test is presented in Figure 11, showing the remaining concrete around the shear stud.

Concrete pull-out failure occurs when the concrete surface fails due to tension occurring across the failure surface. It has been shown that standard push-tests are dominated by failure of the concrete around the shear connectors, as was observed in these tests, rather than shearing of the shear connector itself (Smith, 2009). The typical failure surface for single shear connectors is a cone of concrete starting underneath the head of the shear connector and growing in diameter down the length of the shear connector, although the shape is restricted by the shape of the decking (see Figure 11). However, this type of failure would be less likely to occur in a real composite member which is loaded in bending and, for this reason, many researchers have added a lateral load to the test specimens (e.g. Easterling et al., 1993; Rambo-Roddenberry, 2002; Bradford et al., 2006; Smith, 2009; Smith and Couchman, 2010).

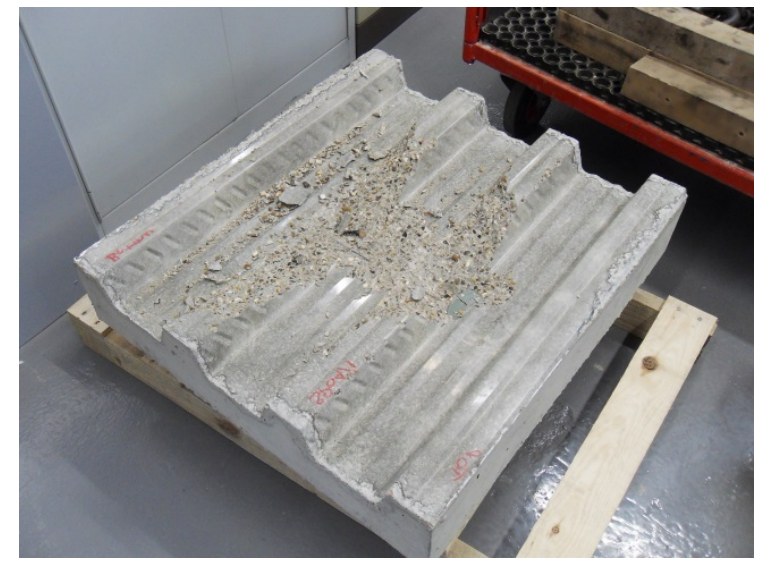

Figure 10 - Failed specimen - concrete

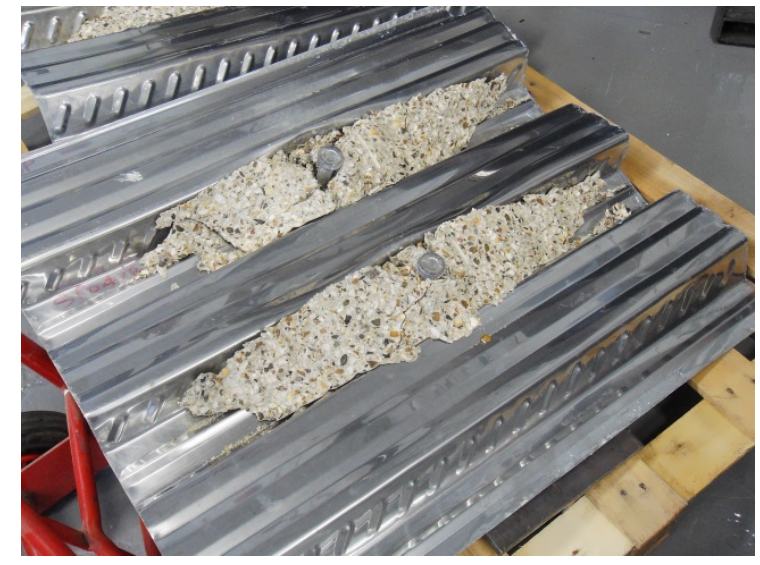

Figure 11 - Failed specimen - decking

As stated previously, all of the slabs behaved very similarly, regardless of the construction form and all failed in an identical manner. As expected, the Series 2 specimens which were through-deck welded and offered continuity of the steel sheeting demonstrated higher load and slip capacities. Also, during the unloading stage of the load-slip response, these slabs were more ductile than the specimens with punched holes. The combination of the throughdeck welded shear studs and the continuous steel sheeting enhanced the bond strength and consequently the load and slip capacity of the slab. Previous studies have shown that composite specimens with pre-punched holes (i.e. Series 3) offer the advantage of producing more reliable and better stud welds with fewer failures (Ernst et al., 2009), but there was no issue with the through-deck welded studs in this test programme.

It is noteworthy that the response of Specimen 1-A was quite different to the other slabs in that it had a considerably lower load resistance, much greater slip capacity and the shape of overall load-slip relationship was quite dissimilar to the other tests (refer to Figure 6). This is due to experimental error at the time of casting. This was the first specimen to be cast in this programme and the concrete mixture was quite 'lumpy' and inconsistent. Although it was of acceptable strength on test day $\left(f_{c k}=35.82 \mathrm{~N} / \mathrm{mm}^{2}\right)$, it is thought that the texture and consistency of the concrete affected the bond between the deck and the slab thereby 
causing this test to behave uncharacteristically. The concrete mixture probably added to the mechanical interlock between the slab and the decking allowing more slippage to occur without a loss in bond strength.

\section{COMPARISON BETWEEN THEORETICAL AND EXPERIMENTAL RESULTS}

Using the equations presented earlier in this paper, the reduction factor $\left(\mathrm{k}_{\mathrm{t}}\right)$ for the Cofraplus 60 decks used in these tests is found to equal 0.63 . The design strength ( $\left.P_{\text {Rd,rib }}\right)$ for each of the test specimens is presented in Table 2, together with the ratio of the test resistance to the design resistance. The ratio of $P_{R k} / P_{R d, r i b}$ varied between 0.91 for Specimens 3-A and 3-C and 1.06 for Specimen 2-C. It is clear that this ratio is higher for Series 2 relative to Series 3 showing that the through-deck welded shear connectors offer slightly greater shear resistance. In general, given that the design resistance $P_{\text {Rd,rib }}$ values in Table 2 do not include safety $(\mathrm{Y})$ factors, having a 'test to design' ratio of around 1 is as expected.

The ductility of the specimens was reasonable with all of the $\delta_{\mathrm{uk}}$ values being around the $6 \mathrm{~mm}$ value required by the Eurocode in order to justify the assumption of ideal plastic behaviour of the shear connection. As stated before, it has been shown that these types of push tests give lower strength and slip resistances than composite beam specimens. Hicks (2007) showed that studs in beam tests out-performed those in push tests both in terms of resistance and ductility, by $46 \%$ and $269 \%$ respectively. In particular, it has been shown that push test specimens which fail by concrete pull-out as occurred in these tests give brittle failure and low strengths (Johnson and Yuan, 1998).

There is no data in the literature for equivalent tests using galvanised steel decks. However, Bradford et al. (2006) reported some tests which were conducted in a similar manner (i.e. no lateral force applied) and used galvanized decking with a very similar profile shape to the Cofraplus 60 . These tests appeared to show very limited ductility $\left(\delta_{\mathrm{uk}}\right.$ values significantly below $6 \mathrm{~mm}$ ) which the authors attributed to the test arrangement causing premature failure. A new test procedure was proposed wherein a normal force is applied to the specimen in addition to the longitudinal force in order to prevent concrete pull-out failure and unrealistically low ductility.

On this basis, it is reasonable to deduce that specimens with ferritic stainless steel decking behave at least as well as slabs with galvanised decking and therefore conform to the current requirements of the Eurocode specification.

\section{CONCLUSIONS}

This paper has described a series of push tests which were completed as part of a wider project looking at structural applications of ferritic stainless steels (SAFSS). An overview of the project was given followed by an introduction to ferritic stainless steel, including their relevant properties for structural use. One potential application for ferritics is for decking in composite construction and, towards this end, a series of push tests were conducted in order to determine the suitability of these materials for this application and the results presented herein.

The methodology, results and analysis of the push tests were presented, and it was concluded that the resistance of shear connectors is comparable with the resistance given in Eurocode 4 (EN 1994-1-1, 2004) for galvanised decking both when through-deck welded and when directly welded to the steel section through pre-cut holes in the deck. All of the tests failed in the same manner which was through concrete pull-out, regardless of the construction form used. The results also showed that there is sufficient ductility to use the current minimum shear connection rules in Eurocode 4 for headed stud shear connectors. 
It is accepted that the method of testing is not ideal as it creates internal forces which are different to those that occur in composite members under bending forces. However, as a starting point, it is important to complete the tests in accordance with the Eurocode so that comparisons with existing design equations can be made. Further work is required in order to numerically analyse the push test specimens so that the effect of the loading conditions can be quantified and further understood. Specific recommendations or modifications to the Eurocodes have not been proposed as further analysis is required, including a direct comparison with the performance of galvanised steel under identical conditions.

\section{ACKNOWLEDGEMENTS}

The research leading to these results has received funding from the European Community's Research Fund for Coal and Steel (RFCS) under Grant Agreement no. RFSR-CT-201000026, Structural Applications of Ferritic Stainless Steels. The authors would also like to thank the technical staff of the structures laboratories at Brunel University, particularly Malcolm Austen and Keith Withers, for their assistance with the experimental work as well as Zainab Adigun, Olayinka Oladiran and Seyed Ghaffar for their contribution to the specimen preparation and testing.

\section{REFERENCES}

Barnard, N and Ogden, R (1996). The thermal capacity of steel frame buildings. Seminar Paper available from the Steel Construction Institute, UK

Bradford M.A., Filonov A. and Hogan T.J. (2006). Push testing procedure for composite beams with deep trapezoidal slabs. Proceedings of the Eleventh international conference on metal structures, Rzeszow, Poland.

Bradford M.A., Pi Y.-L., Uy B. (2008). Ductility of composite beams with trapezoidal composite slabs. Proceedings of the Sixth International Conference on Composite Construction in Steel and Concrete, Colorado, USA, pp. 151-158.

Cashell K.A. and Baddoo N.R. (2014). Ferritic stainless steels in structural applications. Thin-Walled Structures, In Press, 2014.

Easterling, W. S., Gibbings, D. R., and Murray, T. M. (1993). Strength of Shear Studs in Steel Deck on Composite Beams and Joists. Engineering Journal, AISC, 30(2) pp. 44-55.

EN 1992-1-1 (2004). Eurocode 2-Design of concrete structures - Part 1-1: General rules and rules for buildings. CEN, Brussels, Belgium.

EN 1993-1-2 (2005). Eurocode 3-Design of steel structures, Part 1-2: General rules Structural fire design. CEN, Brussels, Belgium.

EN 1993-1-4 (2006). Eurocode 3-Design of steel structures: Part 1-4: General rules Supplementary rules for stainless steels. CEN, Brussels, Belgium.

EN 1993-1-8 (2005). Eurocode 3-Design of steel structures, Part 1-8: Design of joints, European Committee for Standardisation. CEN, Brussels, Belgium.

EN 1993-1-9 (2005). Eurocode 3-Design of steel structures, Part 1-9: Fatigue. CEN, Brussels, Belgium.

EN 1993-1-10 (2005). Eurocode 3-Design of Steel Structures- Part 1-10: Material toughness and through-thickness properties. CEN, Brussels, Belgium.

EN 1994-1-1 (2004). Eurocode 4.-Design of composite steel and concrete structures Part 1-1: General rules and rules for buildings. CEN, Brussels, Belgium. 
Ernst S., Bridge R. and Wheeler A. (2009). Push-out tests and a new approach for the design of secondary composite beam shear connections. Journal of Constructional Steel Research, 65, pp. 44-53.

Hicks S. (2007). Strength and ductility of headed stud connectors welded in modern profiled steel sheeting. The Structural Engineer, 85(10), pp. 32-38

Johnson R.P. and Yuan H. (1998). Models and design rules for stud shear connectors in troughs of profiled sheeting. Proceedings of the Institution of Civil Engineers Structures and Buildings, 128, pp. 252-263.

Kendrik C. and Wang X (2007). Thermal mass in new build UK housing: a comparison of structural systems in a future weather scenario. Report to the Steel Construction Institute, UK.

Rambo-Roddenberry M. (2002). Behavior and strength of welded stud shear connectors, PhD Thesis, Virginia Polytechnic Institute and State University.

SEI/ASCE (2002). Specification for the Design of Cold-Formed Stainless Steel Structural Members ,SEI/ASCE 8-02.

Simms W.I. and Hughes A.F. (2011). Composite Design of steel framed buildings - In accordance with Eurocodes and the UK National Annexes. Steel Construction Institute (SCI), Ascot, UK.

Smith A.L. (2009). Effect of key variables on shear connector performance using new push rig. SCI Report RT1236, Ascot, UK.

Smith A.L. and Couchman G.H. (2010). Strength and ductility of headed stud shear connectors in profiled steel sheeting. Journal of Constructional Steel Research, 66, pp. 748754.

South African Bureau of Standards (1997). Code of Practise, Structural Use of Steel, Part 4: The Design of Cold-formed Stainless Steel Structural Members, SABS 0162-4:1997.

Standards Australia Standards New Zealand (2001). Cold-formed stainless steel structures, AS/NZS 4673:2001. 